\title{
Urine anti-PLA2R antibody is a novel biomarker of idiopathic membranous nephropathy
}

\author{
Yu Wang ${ }^{1}$, Yi-Xin He ${ }^{1}$, Tian-Tian Diao ${ }^{1}$, Shi-Yao Wei ${ }^{1}$, Wen-Rui Qi ${ }^{2}$, Cen-Cen Wang ${ }^{1}$, \\ Shu-Min Song ${ }^{1}$, Min Bi ${ }^{1}$, Chun-Mei Li ${ }^{1}$, Cai-Xia Zhang ${ }^{1}$, Yan-Pei Hou ${ }^{1}$, Qiu-Ju Wei ${ }^{1}$ \\ and Bing Li ${ }^{1}$ \\ ${ }^{1}$ Department of Nephrology, Second Affiliated Hospital of Harbin Medical University, Harbin, People's Republic of China \\ ${ }^{2}$ Science and Technology Department, Financial Mathematics Major, Beijing Normal University, Hong Kong Baptist University \\ United International College, Zhuhai, People's Republic of China \\ Correspondence to: Bing Li, email: icecreamlee@hotmail.com \\ Keywords: idiopathic membranous nephropathy, urine anti-PLA2R antibody, proteinuria, biomarker, diagnosis, Immunology and \\ Microbiology Section, Immune response, Immunology \\ $\begin{array}{lll}\text { Received: May 02, } 2017 & \text { Accepted: July 25, } 2017 & \text { Published: August 03, } 2017\end{array}$
}

Copyright: Wang et al. This is an open-access article distributed under the terms of the Creative Commons Attribution License 3.0 (CC BY 3.0), which permits unrestricted use, distribution, and reproduction in any medium, provided the original author and source are credited.

\section{ABSTRACT}

Since urine samples more directly reflect kidney alterations and damage than blood samples, we investigated whether urine anti-PLA $R$ antibody (UPLA $R-A b$ ) could be utilized similarly to serum anti-PLA $R$ antibody (sPLA $R-A b)$ as a noninvasive biomarker of idiopathic membranous nephropathy (IMN). In this study, we performed a qualitative analysis using an indirect immunofluorescence test (IIFT) and measured uPLA ${ }_{2} R-A b$ and $S P L A_{2} R-A b$ concentrations using an enzyme-linked immunosorbent assay (ELISA) in 28 patients with biopsy-proven IMN and 12 patients with secondary membranous nephropathy (SMN). Overall, $64.3 \%(n=18)$ of patients with IMN had IIFT-positive SPLA $_{2} R-A b, 67.9 \%(n=19)$ of patients with IMN had IIFT-positive uPLA,R-Ab, and none of the SMN patients had IIFT-positive SPLA, R-Ab or uPLA,R-Ab. The titers of the anti-PLA $R$ antibody from the IMN patients in the urine $(10.72 \pm 22.24$ $\mathrm{RU} / \mu \mathrm{mol}$, presented as uPLA ${ }_{2} \mathrm{R}-\mathrm{Ab} /$ urine creatinine) and serum (107.36 $140.93 \mathrm{RU} /$ $\mathrm{ml})$ were higher than those from the SMN patients $(0.51 \pm 0.46 \mathrm{RU} / \mu \mathrm{mol}, 0.008 \pm 0.029$ $\mathrm{RU} / \mathrm{ml}$, respectively, $p<0.05)$. Statistical analyses indicated that there were positive correlations between uPLA ${ }_{2} R-A b$ and gPLA $_{2} R_{\text {, }}$ SPLA 2 R-Ab or urinary protein and negative correlations between $u P L A_{2} R-A b$ and serum albumin in patients with IMN. In conclusion, $u$ PLA $A_{2} R-A b$ is a novel biomarker of IMN. SPLA 2 R-Ab combined with uPLA ${ }_{2} R-A b$ might be more helpful for diagnosis and activity in PLA $R$ associated MN.

\section{INTRODUCTION}

Membranous nephropathy (MN) is a major cause of nephrotic syndrome in adults [1-3], a leading cause of end-stage renal disease in patients with primary glomerulonephritis and the primary glomerulonephritis that recurs after kidney transplantation [4]. Although an accurate pathological diagnosis can be made using immunofluorescence, light microscopy and electron microscopy [5], the definitive pathophysiology of idiopathic membranous nephropathy remains unclear. In the early 2000s, neutral endopeptidase was identified as the first human podocyte antigen involved in neonatal alloimmune membranous nephropathy [6], and recent advances have been achieved toward an understanding of the pathophysiology of membranous nephropathy.
Currently, IMN is considered an autoimmune disease due to the landmark discovery of the phospholipase $\mathrm{A}_{2}$ receptor $\left(\mathrm{PLA}_{2} \mathrm{R}\right)$, which was found to be targeted by circulating antibodies in $70 \%-80 \%$ of adult patients with IMN [7]. In addition to PLA ${ }_{2} \mathrm{R}$, thrombospondin type-1 domain-containing 7A (THSD7A) is another relevant autoantigen, and circulating autoantibodies against this protein have been detected in $5-10 \%$ of patients who are negative for anti-PLA ${ }_{2} \mathrm{R}[8]$.

However, the exact mechanism of $\mathrm{PLA}_{2} \mathrm{R}$-induced IMN is unknown. Genome-wide association studies have reported that the 6p21 HLA-DQA1 and 2q24PLA $R 1$ loci are related to IMN in White European patients [9]. Furthermore, data from various cohorts in Europe [10, 11] and Asia [12-14] supported the observation that individuals who carried the risk alleles of the two genes 
described above tended to develop IMN.

Currently, tests to measure anti-PLA $\mathrm{R}_{2}$ antibodies in the serum and to detect the $\mathrm{PLA}_{2} \mathrm{R}$ antigen in glomerular deposits can be performed routinely [4]. The following two standardized assays from EUROIMMUN are thought to be suitable for routine diagnostic purposes: an indirect immunofluorescence test (IIFT) and an enzyme-linked immunosorbent assay (ELISA) [5]. Many publications by us [15] and other researchers have confirmed the value of serum anti-PLA ${ }_{2} \mathrm{R}$ antibody ( $\mathrm{SPLA}_{2} \mathrm{R}-\mathrm{Ab}$ ) and glomerular $\mathrm{PLA}_{2} \mathrm{R}\left(\mathrm{gPLA}_{2} \mathrm{R}\right)$ in the diagnosis and monitoring of patients with IMN and the prediction of post-transplantation recurrence $[10,16-20]$. A study that described a urine test for the early detection of kidney injury molecule-1 (Kim-1) inspired us to design an analogous test for the detection of the anti-PLA ${ }_{2} \mathrm{R}$ antibody in urine because urine samples more directly reflect kidney damage and alterations than do blood samples. Thus, the aim of this study was to determine whether urinary anti$\mathrm{PLA}_{2} \mathrm{R}$ antibody ( $\mathrm{uPLA} \mathrm{A}_{2} \mathrm{R}-\mathrm{Ab}$ ) levels could serve as a noninvasive indicator for the diagnosis of IMN and could reflect IMN activity and severity.

\section{RESULTS}

\section{Clinical characteristics of patients with IMN or SMN}

A total of 28 patients with biopsy-proven IMN and 12 patients with SMN were recruited in this study. We simultaneously collected serum and urine samples before biopsy. The renal pathology diagnosis referred to the immunofluorescence results of gPLA $\mathrm{R}_{2} \mathrm{R}$ and $\mathrm{IgG}$ subtypes (Figures 1a-1b), as in our previous study [15]. All IMN patients were both gPLA $_{2}$ R- and IgG4-positive, but SMN patients were negative. Among the 12 SMN patients, 7 patients were diagnosed with systemic lupus erythematosus, 3 with connective tissue disease, and 2 with hepatitis B virus (HBV)-associated nephritis. As shown in Table 1, IMN patients were predominantly male, while more female patients $(p<0.05)$ were found in the SMN group. No significant differences in weight, age, proteinuria, serum albumin, serum creatinine or estimated glomerular filtration rate (eGFR) were found between IMN and SMN patients.

\section{uPLA 2 R-Ab is a good noninvasive indicator for IMN diagnosis}

In this study, we determined that $64.3 \%(n=18)$ of patients with IMN were sPLA 2 R-Ab-positive by qualitative analysis by IIFT. Urine more specifically reflects kidney injury than does blood. Thus, uPLA $\mathrm{R}-\mathrm{Ab}$ was examined in the present study. Surprisingly, $67.9 \%$ $(n=19)$ of patients with IMN were $\mathrm{uPLA}_{2} \mathrm{R}-\mathrm{Ab}$-positive (Figure 1k). Of these patients, 17 were simultaneously ${ }_{\text {sPLA }} \mathrm{R}-\mathrm{Ab}$ - and $\mathrm{uPLA}_{2} \mathrm{R}-\mathrm{Ab}$-positive. In contrast, no serum or urine sample from the SMN group was positive for the anti-PLA ${ }_{2} \mathrm{R}$ antibody (Figures $\left.1 \mathrm{c}-1 \mathrm{j}\right)$. Furthermore, we performed quantitative analysis by ELISA (Table 1). The titers of sPLA R-Ab $(p<0.01)$ and uPLA 2 R-Ab $(p<$ 0.05 ) from the IMN group were significantly higher than those from the SMN patients (Figures 11-1m).

\section{uPLA 2 R-Ab titer is highly correlated with SPLA 2 R-Ab level in patients with IMN}

We further investigated the association between the $\mathrm{uPLA}_{2} \mathrm{R}-\mathrm{Ab}$ titer and gPLA $\mathrm{R}_{2} \mathrm{R}$ intensity. As in our previous study, we divided gPLA $_{2} \mathrm{R}$ IF results into four classes according to the immunofluorescence intensity [15]. To compare the $\mathrm{uPLA}_{2} \mathrm{R}-\mathrm{Ab}$ titers of different patients, we adjusted the ELISA results to the urine creatinine from the same sample and presented the findings as $\mathrm{uPLA}_{2} \mathrm{R}$ $\mathrm{Ab}$ titer/urine creatinine. As shown in Figure 2a, there was a positive correlation between gPLA $_{2} \mathrm{R}$ intensity and the $\mathrm{uPLA}_{2} \mathrm{R}-\mathrm{Ab}$ titer $(R=0.547, p<0.01)$. As reported in our previous study, sPLA R-Ab is a good noninvasive indicator of IMN activity and severity. In addition, monitoring the $\mathrm{SPLA}_{2} \mathrm{R}-\mathrm{Ab}$ titer may assist in the determination of when to initiate the administration of immunosuppressive agents and in the evaluation of treatment efficacy [15]. Thus, we examined the correlation between the levels of uPLA $\mathrm{R}-\mathrm{Ab}$ and the levels of ${ }_{s} P L A_{2} R-A b$. As shown in Figures $2 b-2 c$, there were significant positive correlations between the $\mathrm{uPLA}_{2} \mathrm{R}-\mathrm{Ab}$ titer and the $\mathrm{SPLA}_{2} \mathrm{R}-\mathrm{Ab}$ using both IIFT $(R=0.508, p<$ $0.01)$ and ELISA $(R=0.459, p<0.05)$.

\section{uPLA $A_{2} R-A b$ is a good noninvasive biomarker for IMN activity and severity}

To assess whether the expression of $\mathrm{uPLA}_{2} \mathrm{R}-\mathrm{Ab}$ can indicate IMN disease activity and severity similarly to $\mathrm{SPLA}_{2} \mathrm{R}-\mathrm{Ab}$ [15], the relationship between uPLA R$\mathrm{Ab}$ and the clinical parameters was examined. The IIFT intensity of uPLA $\mathrm{A}_{2} \mathrm{R}-\mathrm{Ab}$ was positively correlated with proteinuria $(R=0.658, p<0.01)$ and was negatively correlated with serum albumin $(R=-0.573, p<0.01)$. uPLA 2 R-Ab titer was positively correlated with proteinuria $(R=0.515, p<0.01)$ but was not significantly correlated with albumin $R=-0.245, p=0.209$ ) (Figures $3 a-3 b)$. We then observed that most $\mathrm{uPLA}_{2} \mathrm{R}-\mathrm{Ab} / \mathrm{urine}$ creatinine values in patients with IMN were $>1 \mathrm{RU} / \mu \mathrm{mol}$, which was defined as a cutoff value in this study. We then divided patients into positive ( $\mathrm{UPLA}_{2} \mathrm{R}-\mathrm{Ab}$ titer/urine creatinine $\geq 1 \mathrm{RU} / \mu \mathrm{mol}$ ) and negative groups $\left(\mathrm{uPLA}_{2} \mathrm{R}\right.$ $\mathrm{Ab}$ titer/urine creatinine $<1 \mathrm{RU} / \mu \mathrm{mol}$ ). According to the rules above, the uPLA $\mathrm{R}-\mathrm{Ab}$ titer was positively correlated 
with proteinuria $(R=0.658, p<0.01)$ and was negatively correlated with serum albumin per ELISA $(R=-0.630, p$ $<0.01$ ) (Figures 3c-3d).

Taken together, these results indicate that $\mathrm{uPLA}_{2} \mathrm{R}$ $\mathrm{Ab}$ may also be a good noninvasive biomarker for IMN activity and severity.

glgG4
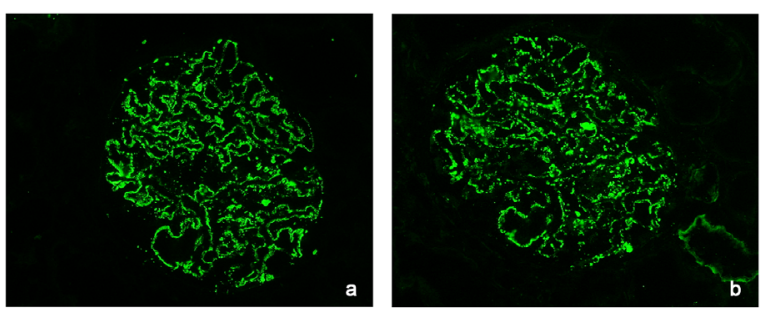

\section{DISCUSSION}

The discovery of a serum anti-PLA 2 R antibody in patients with IMN has led to the clinical application of $\mathrm{sPLA}_{2} \mathrm{R}-\mathrm{Ab}$ for diagnosis, disease activity monitoring, treatment response evaluations, and prognosis [7, 10, 16-20]. Because the evaluation of urinary indicators is a
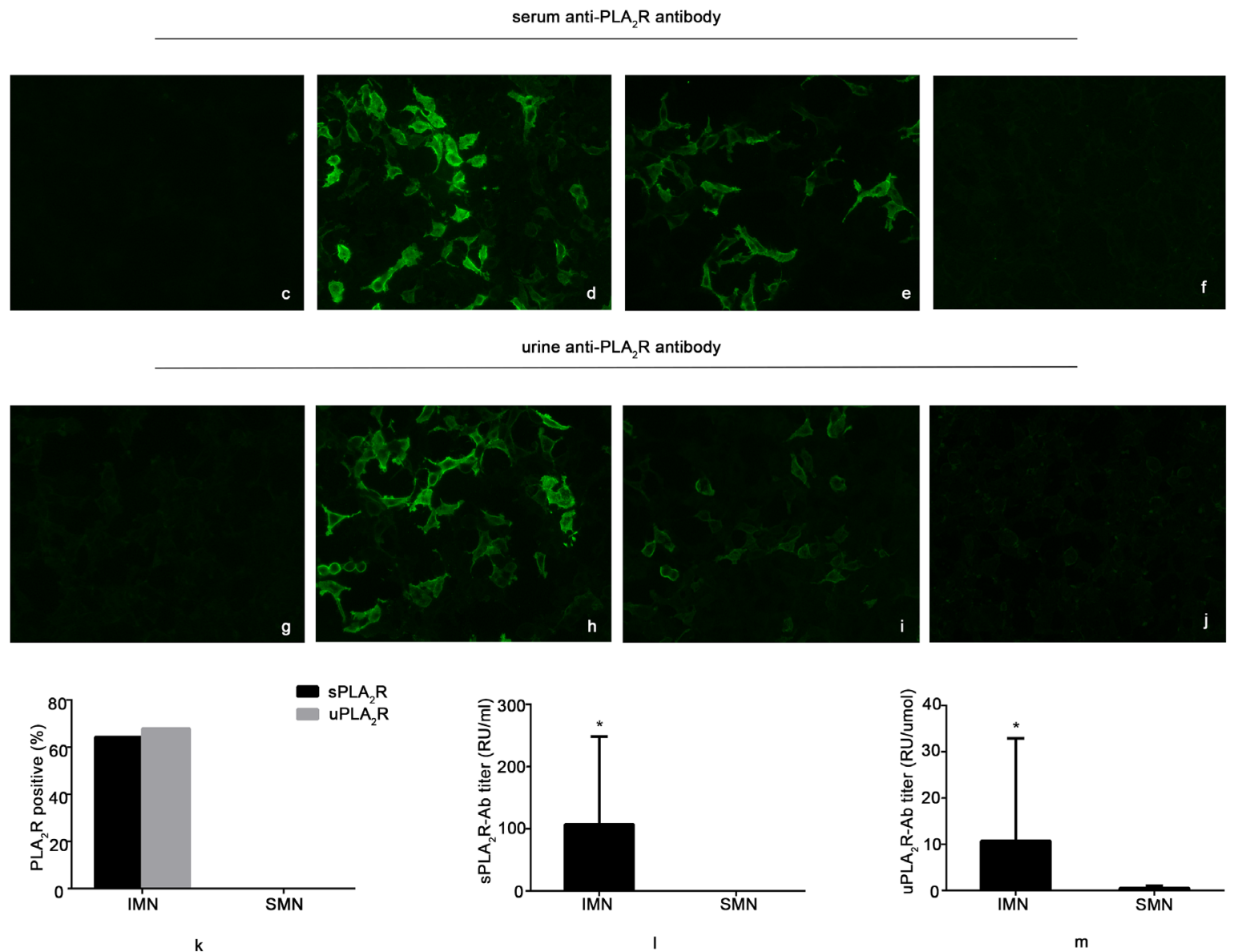

Figure 1: Detection of the expression of serum anti-PLA $A_{2} R$ antibody ( $\left.P L A_{2} R-A b\right)$ and urine anti-PLA 2 antibody (uPLA $A_{2}$-Ab) by indirect immunofluorescence test (IIFT) and enzyme-linked immunosorbent assay (ELISA). a. and b. show one idiopathic membranous nephropathy (IMN) patient in this study who presented as glomerular IgG4- and PLA R immunofluorescence positive. c. and g. show negative control biochips coated with cells that did not express the PLA $\mathrm{R}_{2}$ protein that were incubated with serum and urine samples, respectively. d. and $\mathbf{h}$. show the comparative fluorescence intensities of biochips that were incubated with serum and urine samples, respectively, from patient No. 23 in Supplementary Table 1. e. and i., from patient No. 28, show higher fluorescence intensity in the section incubated with serum than with urine. $\mathbf{f}$. and $\mathbf{j}$., from patient No. 36 with systemic lupus erythematosus, show samples that are negative for sPLA $_{2} \mathrm{R}-\mathrm{Ab}$ or $u \mathrm{PLA}_{2} \mathrm{R}-\mathrm{Ab}$. $\mathbf{k}$. shows the positive expression of sPLA $\mathrm{R}_{2}-\mathrm{Ab}_{\mathrm{b}}$ or $\mathrm{uPLA} \mathrm{R}_{2} \mathrm{R}-$ $\mathrm{Ab}$ in IMN and SMN patients by IIFT. I. and $\mathbf{m}$. show the titers of $\operatorname{sPLA}_{2} \mathrm{R}-\mathrm{Ab}$ or uPLA 2 R-Ab in IMN and SMN patients by ELISA. ${ }^{*} p$ $<0.05$ 
Table 1: Clinical characteristics and SPLA,R-Ab and uPLA,R-Ab titers of the IMN and SMN patients

\begin{tabular}{|c|c|c|c|c|c|c|c|c|c|c|c|c|}
\hline Diagnosis & Number & Gender & Age & $\begin{array}{l}\text { Weight } \\
\text { (kg) }\end{array}$ & $\begin{array}{l}\text { Urinary } \\
\text { protein } \\
(\mathrm{g} / \mathbf{2 4 h})\end{array}$ & $\begin{array}{l}\text { Serum } \\
\text { creatinine } \\
(\mu \mathrm{mol} / \mathrm{L})\end{array}$ & $\begin{array}{l}\text { Serum } \\
\text { albumin } \\
(\mathrm{g} / \mathrm{L})\end{array}$ & $\begin{array}{l}\text { eGFR } \\
\text { (ml/ } \\
\text { min/1.73m2) }\end{array}$ & $\begin{array}{l}\text { sPLA2R-Ab titer } \\
\text { (RU/ml) }\end{array}$ & $\begin{array}{l}\text { uPLA2R-Ab } \\
\text { titer } \\
\text { (RU/ml) }\end{array}$ & $\begin{array}{l}\text { Urine creatinine } \\
(\mu \mathrm{mol} / \mathrm{L})\end{array}$ & $\begin{array}{l}\text { uPLA2R-Ab } \\
\text { titer/ } \\
\text { urine } \\
\text { creatinine } \\
(\mathrm{RU} / \mu \mathrm{mol})\end{array}$ \\
\hline IMN & 28 & $\begin{array}{l}\text { male } \\
17^{*}\end{array}$ & $50.54 \pm 12.67$ & $69.16 \pm 10.02$ & $6.73 \pm 3.36$ & $67.29 \pm 17.29$ & $23.89 \pm 7.19$ & $138.49 \pm 49.59$ & $107.36 \pm 140.93 * *$ & $94.61 \pm 187.57^{*}$ & $9276.79 \pm 5063.30$ & $10.72 \pm 22.24 *$ \\
\hline SMN & 12 & male 2 & $40.17 \pm 7.25$ & $62.79 \pm 14.14$ & $7.83 \pm 7.34$ & $71.63 \pm 26.60$ & $22.73 \pm 8.15$ & $122.07 \pm 41.03$ & $0.01 \pm 0.03$ & $3.36 \pm 2.38$ & $8130.67 \pm 6262.25$ & $0.51 \pm 0.46$ \\
\hline
\end{tabular}

IMN, idiopathic membranous nephropathy; SMN, secondary membranous nephropathy.

Differences in gender were observed between the two groups, and these characteristics may be associated with the etiologies of these two disease subtypes. Serum and urine PLA 2 antibody titers as detected by ELISA in this study. To compare the urine ELISA results among the different samples, the $\mathrm{uPLA}_{2} \mathrm{R}-\mathrm{Ab}$ ELISA results were adjusted to the urine creatinine results. ${ }^{* *} p<0.01,{ }^{*} p<0.05$.

noninvasive and sensitive method for the estimation of proteinuria and for monitoring the therapeutic effects of an intervention, which would be a requirement for an ideal biomarker of IMN, we investigated whether a urinary anti-PLA 2 R antibody could be detected in MN patients. Experimental and human studies of IMN mechanisms have indicated that immunoglobulins along the glomerular basement membrane (GBM) initiate a sequence of events that include complement activation, an impaired sieving function of the glomerular capillary wall and the poreforming slit diaphragm, and eventual proteinuria [21, 22]. In IMN, non-selective proteinuria leakage occurs through the impaired filtration barrier from blood to crude urine. The composition of the crude urine accordingly contains circulating $\mathrm{sPLA}_{2} \mathrm{R}-\mathrm{Ab}$, which crosses the impaired filtration barrier and does not bind $\mathrm{gPLA}_{2} \mathrm{R}$. Thus, we speculated that an anti-PLA $R$ antibody should be found in urine and could be detected by ELISA and IIFT, as with $\mathrm{SPLA}_{2} \mathrm{R}-\mathrm{Ab}$ reported before [15]. In our study, we found that the expression of $\mathrm{UPLA}_{2} \mathrm{R}-\mathrm{Ab}$ was positively correlated with $\mathrm{SPLA}_{2} \mathrm{R}-\mathrm{Ab}$ as detected via ELISA and IIFT. The urinary anti-PLA $\mathrm{R}_{2}$ antibody titer was related to the proteinuria activity and severity and the expression of the serum anti-PLA 2 R antibody. These results confirmed that the urinary anti-PLA 2 antibody could be a biomarker of IMN

Many reports have assessed the $\mathrm{sPLA}_{2} \mathrm{R}$ antibody and the glomerular antigen $\left(\mathrm{gPLA}_{2} \mathrm{R}\right)$ and reported that sPLA $_{2} \mathrm{R}-\mathrm{Ab}$ and $\mathrm{gPLA}_{2} \mathrm{R}$ were not always found at the same time $[23,24]$. This phenomenon was also observed in our previous study [15] and other publications [25-27]. Some patients who had a high level of serum anti-PLA 2 autoantibodies were not PLA R-positive in the glomerular deposits; in contrast, some patients had no detectable serum anti-PLA 2 R autoantibodies but were PLA 2 R-Abpositive in the glomerular deposits. The possible reasons were this finding could be as follows: 1. The former phenomenon might reflect the early stage of $\mathrm{MN}$, because the antibodies remained in circulation in the blood but were poorly accessible at the time of kidney biopsy, and the latter might reflect the recovery or inactive stage of $\mathrm{MN}$. Therefore, the titer of the $\mathrm{sPLA}_{2} \mathrm{R}-\mathrm{Ab}$ returned to normal, and the depositions in the glomeruli could not be cleared completely, resulting in gPLA 2 Rositivity. 2 . Urine samples more directly reflect kidney damage and deposit than blood samples. The inability to detect the sPLA 2 R-Ab, gPLA 2 R and uPLA R-Ab simultaneously may reflect that the different stages of IMN. Therefore,
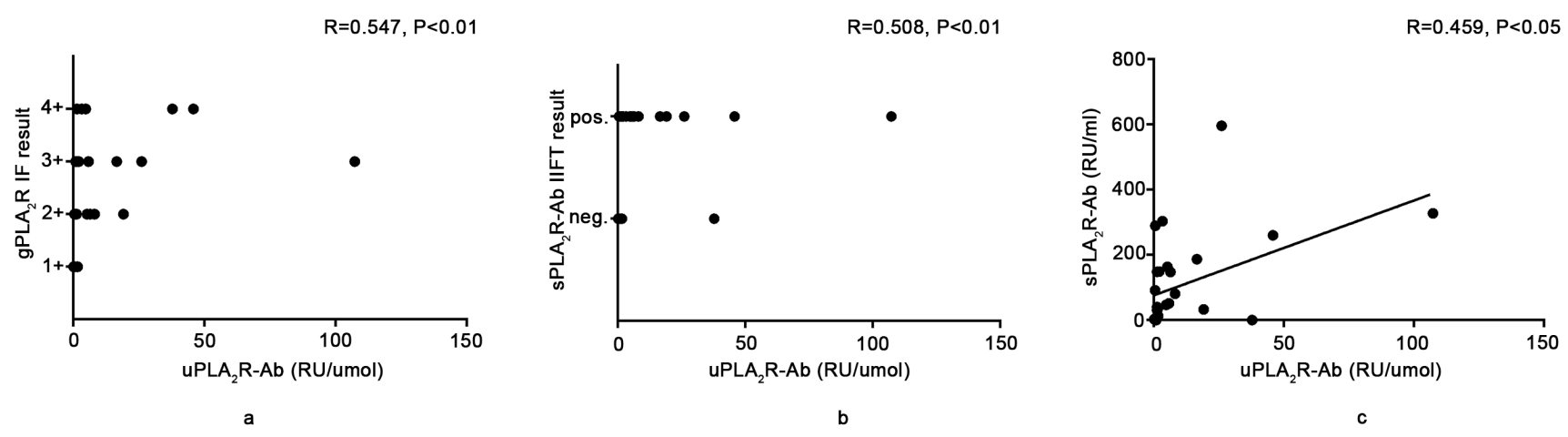

Figure 2: Relationship between the urine anti-PLA $A_{2} R$ antibody titer and glomerular PLA 2 antigen (gPLA $R$ ) or serum anti-PLA $A_{2} R$ antibody titer. a. shows the positive relationship between gPLA $R$ IIFT intensity and the $u P L A_{2} R-A b$ titer. $b$. and c. show the positive relationship between the $\mathrm{PPLA}_{2} \mathrm{R}-\mathrm{Ab}$ IIFT intensity or titer and uPLA $\mathrm{R}-\mathrm{Ab}$ titer. To compare the $u$ PLA $\mathrm{R}_{2}-\mathrm{Ab}_{\mathrm{b}}$ titer from different patients, we adjusted the values to uPLA2R-Ab/urine creatinine. 
sPLA $_{2} \mathrm{R}-\mathrm{Ab}$ combined with $\mathrm{UPLA}_{2} \mathrm{R}-\mathrm{Ab}$ might be more helpful in the diagnosis and activity assessment of PLA $\mathrm{A}_{2}$ associated MN.

Notably, we observed that one patient with SMN (No.31) was uPLA $_{2}$ R-ab positive (Supplementary Table 2). Similar results were also reported in our previous study and in studies by other research groups [28, 29]. These authors found that a few patients with SMN were $\mathrm{SLA}_{2} \mathrm{R}$ $\mathrm{Ab}$ - or gPLA2R-positive. We believe that these patients most likely represent the occurrence of IMN and SMN; however, the precise mechanism remains unclear.

$\mathrm{SPLA}_{2} \mathrm{R}-\mathrm{Ab}$ detection by IIFT and ELISA should be considered an advance compared with the immunofluorescence detection of gPLA $_{2} \mathrm{R}$ because noninvasive serology tests that replace re-biopsy are more convenient and can be used to reflect the activity and to monitor the response to treatment. In particular, for some patients unable to undergo the biopsy, $\mathrm{SPAA}_{2} \mathrm{R}$ $\mathrm{Ab}$ detection may replace biopsy to some extent. In our study, uPLA 2 R-Ab was similar to $\mathrm{sPLA}_{2} \mathrm{R}-\mathrm{Ab}$ [15] and was positively correlated with proteinuria and negatively correlated with albumin. The titers of $\mathrm{uPLA}_{2} \mathrm{R}-\mathrm{Ab}$ as detected via ELISA were parallel with the titers of sPLA $_{2} \mathrm{R}-\mathrm{Ab}$ as detected via ELISA. We used IIFT and ELISA to assess a 52-year-old male patient who had nephrotic range proteinuria and deep vein thrombosis who was unsuitable for biopsy. His serum and urine IIFT were positive and the SPLA R-Ab and $\mathrm{UPLA}_{2} \mathrm{R}-\mathrm{Ab} / \mathrm{urine}$

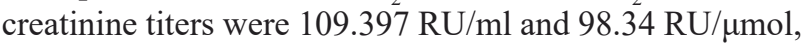
respectively. Although we did not perform a biopsy for him, a definitive diagnosis of IMN could still be made, and the high PLA 2 R-Ab titers found in this patient's blood and urine were consistent with his disease activity.

A recent study indicated that the evaluation of the levels of $\mathrm{sPLA}_{2} \mathrm{R}-\mathrm{Ab}$ and the detection of $\mathrm{gPLA}_{2} \mathrm{R}$ deposition may provide additional information [30]. For instance, of the gPLA $_{2} \mathrm{R}+$ patients, the $\mathrm{sPA}_{2} \mathrm{R}-\mathrm{Ab}+$ patients exhibited greater proteinuria and a lower chance of proteinuria remission than the $\mathrm{gPLA}_{2} \mathrm{R}$ - patients. Urine samples more directly reflect kidney alterations and damage than blood samples. In conclusion, $\mathrm{uPLA}_{2} \mathrm{R}-\mathrm{Ab}$ is a novel biomarker of IMN. sPLA $\mathrm{R}-\mathrm{Ab}$ combined with $\mathrm{uPLA}_{2} \mathrm{R}-\mathrm{Ab}$ might be more helpful in the diagnosis and activity assessment of $\mathrm{PLA}_{2} \mathrm{R}$-associated $\mathrm{MN}$.

$R=-0.245, p=0.209$

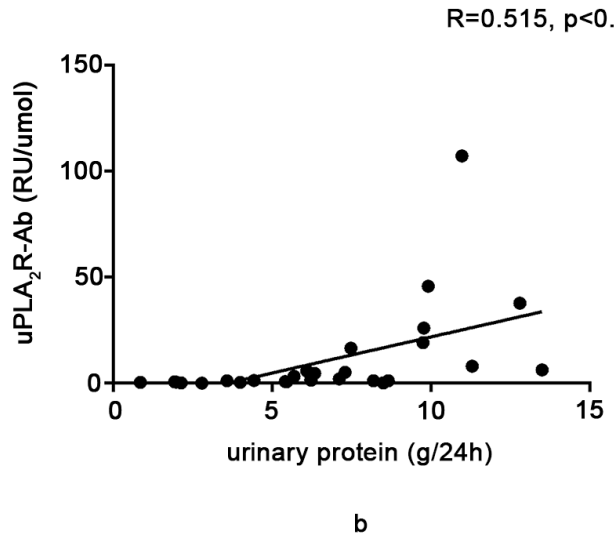

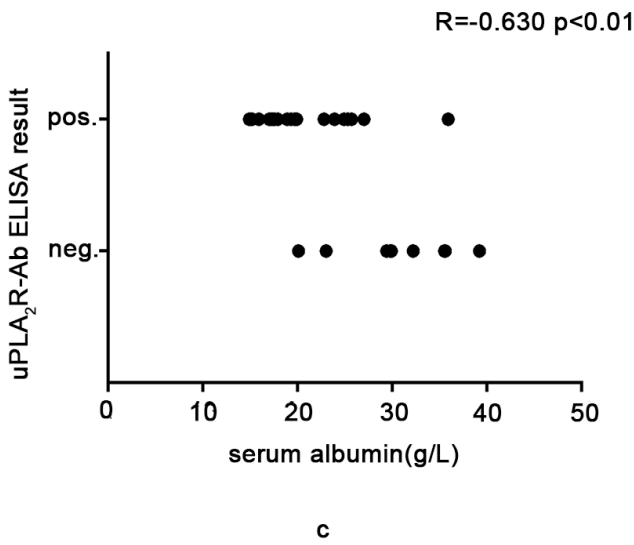

$R=0.658, p<0.01$

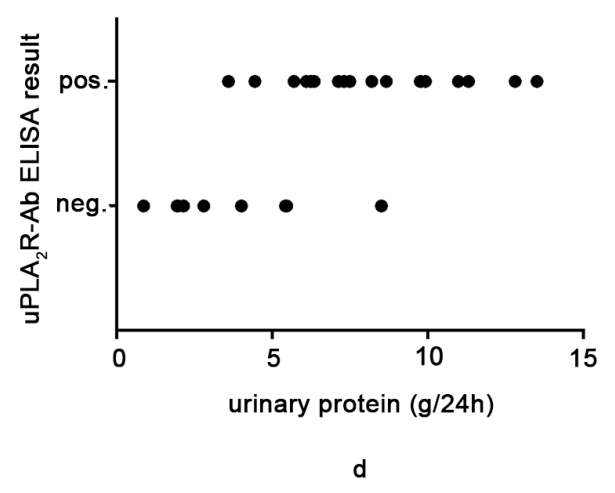

Figure 3: Relationship between the expression of the urine anti-PLA $R$ antibody and the clinical parameters. a. and b. show the relationship between the $\mathrm{UPLA}_{2} \mathrm{R}-\mathrm{Ab}$ titer, measured via ELISA, and the serum albumin level or proteinuria. A statistically significant positive relationship was found between the $\mathrm{uPLA}_{2} \mathrm{R}-\mathrm{Ab}$ titer and proteinuria. If we defined the cutoff of $\mathrm{uPLA} 2 \mathrm{R}-\mathrm{Ab} / \mathrm{urine}$ creatinine by ELISA as $1 \mathrm{RU} / \mu \mathrm{mol}$ in $\mathbf{c}$. and $\mathbf{d}$., we found that there were statistically significant relationships between the $u P L A{ }_{2} \mathrm{R}-\mathrm{Ab}$ titer and the serum albumin level or proteinuria. 


\section{MATERIALS AND METHODS}

\section{Patients and samples}

In this study, 28 patients with biopsy-proven IMN and 12 patients with SMN who were diagnosed between 2015 and 2016 were enrolled from the Second Affiliated Hospital of Harbin Medical University. The 12 SMN patients included 7 who were diagnosed with systemic lupus erythematosus, 3 who were diagnosed with connective tissue disease, and 2 who were diagnosed with $\mathrm{HBV}$-associated nephritis. The pathologic diagnosis of membranous nephropathy was made by light microscopy, immunofluorescence and electron microscopy.

Diagnosis of IMN was established by the following criteria [31]: Kidney biopsy with evidence of immune and electron-dense sub-epithelial deposits, without any deposition in sub-endothelial or mesangial areas. NO glomerular infiltrating cells or proliferation of mesangial and endothelial cells. IgG deposition, with a granular pattern, along the glomerular capillary walls (in association or not with the $\mathrm{C} 3$ complement fraction) proven by immunofluorescence. Secondary causes of MN were excluded after extensive clinical workup including detailed medical history and patient examination, serological markers of systemic autoimmunity such as anti-nuclear anti-bodies, anti-dsDNA, anti-ribonucleoproteins, antiSmith, anti-Ro (SSA), anti-Ro (SSB), anti-topoisomerase I (SCI-70), anti-centromere, anti-Jo-l, anti-cardiolipin, anti$\beta 2$-glycoprotein I antibodies and thyroid autoimmunity. Viral hepatitis B and C and HIV infections, neoplastic conditions and exposure to toxic agents were also ruled out.

\section{Measurement of $\operatorname{sPLA}_{2} \mathrm{R}-\mathrm{Ab}$ and $\mathrm{uPLA}_{2} \mathrm{R}-\mathrm{Ab}$}

Blood and urine samples of all enrolled patients were collected at different time points. SPLA $2-A b$ and $\mathrm{uPLA}_{2} \mathrm{R}-\mathrm{Ab}$ were measured in all patients with an indirect immunofluorescence test (EUROIMMUN AG, Lübeck, Schleswig-Holstein, Germany) and an ELISA test (EUROIMMUN AG, Lübeck, Schleswig-Holstein, Germany) according to the manufacturer's instructions. The serum ELISA results were considered positive at a level of $>20 \mathrm{RU} / \mathrm{ml}$. Although there is no recommended cutoff value or dilution ratio for the urine ELISA, we attempted different dilution ratios (including 1:10, 1:50, $1: 100,1: 200$, and 1:1000). Finally, we found that when the urine samples were diluted 1:10, $\mathrm{uPLA}_{2} \mathrm{R}-\mathrm{Ab}$ could be detected in the samples. To compare the urine ELISA results from different samples, we adjusted the urine ELISA results to the urine creatinine values of the same sample. Most uPLA ${ }_{2} \mathrm{R}-\mathrm{Ab} /$ urine creatinine values were
$>1 \mathrm{RU} / \mu \mathrm{mol}$ in patients with IMN, so we defined this as a cutoff value in this study for the statistical analysis; whether this value indicates two subtypes needs further research.

\section{Statistical analyses}

All analyses were performed using SPSS 19.0 software. The data are expressed as the means \pm SD . Distributions between groups were assessed using the chisquare test and $T$-test; differences of the serum or urine titers by ELISA between the IMN and SMN group were analyzed with $T$-test; agreement between sPLA $\mathrm{R}-\mathrm{Ab}$ and $\mathrm{uPLA}_{2} \mathrm{R}-\mathrm{Ab}$ and the correlations between proteinuria, albumin and $\mathrm{uPLA}_{2} \mathrm{R}-\mathrm{Ab}$ were analyzed with Pearson or Spearman's rank correlation coefficients.

\section{Abbreviations}

urine anti-PLA2R antibody (uPLA2R-Ab); serum anti-PLA2R antibody (sPLA2R-Ab); indirect immunofluorescence test (IIFT); enzyme-linked immunosorbent assay (ELISA); secondary membranous nephropathy (SMN); Idiopathic Membranous Nephropathy (IMN); thrombospondin type-1 domain-containing 7A (THSD7A); glomerular PLA2R (gPLA2R); kidney injury molecule-1 (Kim-1); hepatitis B virus (HBV)-associated nephritis; estimated glomerular filtration rate (eGFR); glomerular basement membrane (GBM).

\section{Author contributions}

Yu Wang performed experiments and wrote the manuscript; Yi-Xin He, Tian-Tian Diao, Shi-Yao Wei, and Wen-Rui Qi analyzed data; Cen-Cen Wang, Shu-Min Song, Min Bi, Chun-Mei Li, Cai-Xia Zhang, Hou-Yan Pei and Qiu-Ju Wei performed experiments; Bing Li designed the study and edited manuscript; all authors collected samples and reviewed the manuscript.

\section{CONFLICTS OF INTEREST}

The authors declare no competing financial interests.

\section{FUNDING}

This study was supported by research grants from the National Natural Science Foundation of China (No. 81670616 and No. 81370812) and a research fund from the Doctoral Program of the Ministry of Education of China (20122307110018). 


\section{REFERENCES}

1. Peng L, Wei SY, Li LT, He YX, Li B. Comparison of different therapies in high-risk patients with idiopathic membranous nephropathy. J Formos Med Assoc. 2016; 115: 11-8. doi: 10.1016/j.jfma.2015.07.021.

2. Chan CK, Lai TS, Chen PM, Chou YH, Wu CF, Chiu YL, Chiang WC, Chen YM, Chu TS, Wu KD. Early initiation of immunosuppressive treatment in membranous nephropathy patients. J Formos Med Assoc. 2017; 116: 266-75. doi: 10.1016/j.jfma.2017.01.004.

3. Lai WL, Yeh TH, Chen PM, Chan CK, Chiang WC, Chen YM, Wu KD, Tsai TJ. Membranous nephropathy: a review on the pathogenesis, diagnosis, and treatment. J Formos Med Assoc. 2015; 114: 102-11. doi: 10.1016/j. jfma.2014.11.002.

4. Ronco P, Debiec H. Pathophysiological advances in membranous nephropathy: time for a shift in patient's care. Lancet. 2015; 385: 1983-92. doi: 10.1016/S01406736(15)60731-0.

5. Mastroianni-Kirsztajn G, Hornig N, Schlumberger W. Autoantibodies in renal diseases - clinical significance and recent developments in serological detection. Front Immunol. 2015; 6: 221. doi: 10.3389/fimmu.2015.00221.

6. Debiec H, Guigonis V, Mougenot B, Decobert F, Haymann JP, Bensman A, Deschenes G, Ronco PM. Antenatal membranous glomerulonephritis due to anti-neutral endopeptidase antibodies. N Engl J Med. 2002; 346: 2053 60. doi: 10.1056/NEJMoa012895.

7. Beck LH Jr, Bonegio RG, Lambeau G, Beck DM, Powell DW, Cummins TD, Klein JB, Salant DJ. M-type phospholipase A2 receptor as target antigen in idiopathic membranous nephropathy. N Engl J Med. 2009; 361: 11-21. doi: 10.1056/NEJMoa0810457.

8. Tomas NM, Beck LH Jr, Meyer-Schwesinger C, SeitzPolski B, Ma H, Zahner G, Dolla G, Hoxha E, Helmchen U, Dabert-Gay AS, Debayle D, Merchant M, Klein J, et al. Thrombospondin type-1 domain-containing 7A in idiopathic membranous nephropathy. N Engl J Med. 2014; 371: 2277-87. doi: 10.1056/NEJMoa1409354.

9. Stanescu HC, Arcos-Burgos M, Medlar A, Bockenhauer D, Kottgen A, Dragomirescu L, Voinescu C, Patel N, Pearce K, Hubank M, Stephens HA, Laundy V, Padmanabhan S, et al. Risk HLA-DQA1 and PLA(2)R1 alleles in idiopathic membranous nephropathy. N Engl J Med. 2011; 364: 61626. doi: 10.1056/NEJMoa1009742.

10. Kanigicherla D, Gummadova J, McKenzie EA, Roberts SA, Harris S, Nikam M, Poulton K, McWilliam L, Short CD, Venning M, Brenchley PE. Anti-PLA2R antibodies measured by ELISA predict long-term outcome in a prevalent population of patients with idiopathic membranous nephropathy. Kidney Int. 2013; 83: 940-8. doi: 10.1038/ki.2012.486.

11. Bullich G, Ballarin J, Oliver A, Ayasreh N, Silva I, Santin
S, Diaz-Encarnacion MM, Torra R, Ars E. HLA-DQA1 and PLA2R1 polymorphisms and risk of idiopathic membranous nephropathy. Clin J Am Soc Nephrol. 2014; 9: 335-43. doi: 10.2215/CJN.05310513.

12. Lv J, Hou W, Zhou X, Liu G, Zhou F, Zhao N, Hou P, Zhao M, Zhang H. Interaction between PLA2R1 and HLADQA1 variants associates with anti-PLA2R antibodies and membranous nephropathy. J Am Soc Nephrol. 2013; 24: 1323-9. doi: 10.1681/ASN.2012080771.

13. Liu YH, Chen CH, Chen SY, Lin YJ, Liao WL, Tsai CH, Wan L, Tsai FJ. Association of phospholipase A2 receptor 1 polymorphisms with idiopathic membranous nephropathy in Chinese patients in Taiwan. J Biomed Sci. 2010; 17: 81. doi: 10.1186/1423-0127-17-81.

14. Kim S, Chin HJ, Na KY, Kim S, Oh J, Chung W, Noh JW, Lee YK, Cho JT, Lee EK, Chae DW, Progressive Renal D, Medical I, et al. Single nucleotide polymorphisms in the phospholipase A2 receptor gene are associated with genetic susceptibility to idiopathic membranous nephropathy. Nephron Clin Pract. 2011; 117: c253-8. doi: $10.1159 / 000320194$.

15. Wei SY, Wang YX, Li JS, Zhao SL, Diao TT, Wang Y, Wang C, Qin Y, Cao Y, Wei Q, Li B. Serum Anti-PLA2R Antibody Predicts Treatment Outcome in Idiopathic Membranous Nephropathy. Am J Nephrol. 2016; 43: 12940. doi: 10.1159/000445361.

16. Bech AP, Hofstra JM, Brenchley PE, Wetzels JF. Association of anti-PLA(2)R antibodies with outcomes after immunosuppressive therapy in idiopathic membranous nephropathy. Clin J Am Soc Nephrol. 2014; 9: 1386-92. doi: $10.2215 /$ CJN.10471013.

17. Hoxha E, Harendza S, Pinnschmidt H, Panzer U, Stahl RA. M-type phospholipase A2 receptor autoantibodies and renal function in patients with primary membranous nephropathy. Clin J Am Soc Nephrol. 2014; 9: 1883-90. doi: 10.2215/ CJN.03850414.

18. Ruggenenti P, Debiec H, Ruggiero B, Chianca A, Pelle T, Gaspari F, Suardi F, Gagliardini E, Orisio S, Benigni A, Ronco P, Remuzzi G. Anti-Phospholipase A2 Receptor Antibody Titer Predicts Post-Rituximab Outcome of Membranous Nephropathy. J Am Soc Nephrol. 2015; 26: 2545-58. doi: 10.1681/ASN.2014070640.

19. Hoxha E, Thiele I, Zahner G, Panzer U, Harendza S, Stahl RA. Phospholipase A2 receptor autoantibodies and clinical outcome in patients with primary membranous nephropathy. J Am Soc Nephrol. 2014; 25: 1357-66. doi: 10.1681/ASN.2013040430.

20. Beck LH Jr, Fervenza FC, Beck DM, Bonegio RG, Malik FA, Erickson SB, Cosio FG, Cattran DC, Salant DJ. Rituximab-induced depletion of anti-PLA2R autoantibodies predicts response in membranous nephropathy. J Am Soc Nephrol. 2011; 22: 1543-50. doi: 10.1681/ ASN.2010111125.

21. Cybulsky AV, Quigg RJ, Salant DJ. Experimental membranous nephropathy redux. Am J Physiol 
Renal Physiol. 2005; 289: F660-71. doi: 10.1152/ ajprenal.00437.2004.

22. Takano T, Elimam H, Cybulsky AV. Complement-mediated cellular injury. Semin Nephrol. 2013; 33: 586-601. doi: 10.1016/j.semnephrol.2013.08.009.

23. Debiec H, Ronco P. PLA2R autoantibodies and PLA2R glomerular deposits in membranous nephropathy. N Engl J Med. 2011; 364: 689-90. doi: 10.1056/NEJMc1011678.

24. Hoxha E, Kneissler U, Stege G, Zahner G, Thiele I, Panzer U, Harendza S, Helmchen UM, Stahl RA. Enhanced expression of the M-type phospholipase A2 receptor in glomeruli correlates with serum receptor antibodies in primary membranous nephropathy. Kidney Int. 2012; 82: 797-804. doi: 10.1038/ki.2012.209.

25. Guerry MJ, Vanhille P, Ronco P, Debiec H. Serum anti-PLA2R antibodies may be present before clinical manifestations of membranous nephropathy. Kidney Int. 2016; 89: 1399. doi: 10.1016/j.kint.2015.11.032.

26. van de Logt AE, Hofstra JM, Wetzels JF. Serum antiPLA2R antibodies can be initially absent in idiopathic membranous nephropathy: seroconversion after prolonged follow-up. Kidney Int. 2015; 87: 1263-4. doi: 10.1038/ ki.2015.34.

27. Bally S, Debiec H, Ponard D, Dijoud F, Rendu J, Faure J, Ronco P, Dumestre-Perard C. Phospholipase A2 ReceptorRelated Membranous Nephropathy and Mannan-Binding Lectin Deficiency. J Am Soc Nephrol. 2016; 27: 3539-44. doi: 10.1681/ASN.2015101155.
28. Larsen CP, Messias NC, Silva FG, Messias E, Walker PD. Determination of primary versus secondary membranous glomerulopathy utilizing phospholipase A2 receptor staining in renal biopsies. Mod Pathol. 2013; 26: 709-15. doi: 10.1038/modpathol.2012.207.

29. Qin W, Beck LH Jr, Zeng C, Chen Z, Li S, Zuo K, Salant DJ, Liu Z. Anti-phospholipase A2 receptor antibody in membranous nephropathy. J Am Soc Nephrol. 2011; 22: 1137-43. doi: 10.1681/ASN.2010090967.

30. Qin HZ, Zhang MC, Le WB, Ren Q, Chen DC, Zeng CH, Liu L, Zuo K, Xu F, Liu ZH. Combined Assessment of Phospholipase A2 Receptor Autoantibodies and Glomerular Deposits in Membranous Nephropathy. J Am Soc Nephrol. 2016; 27: 3195-203. doi: 10.1681/ASN.2015080953.

31. Radice A, Trezzi B, Maggiore U, Pregnolato F, Stellato T, Napodano P, Rolla D, Pesce G, D'Amico M, Santoro D, Londrino F, Ravera F, Ortisi G, et al. Clinical usefulness of autoantibodies to M-type phospholipase A2 receptor (PLA2R) for monitoring disease activity in idiopathic membranous nephropathy (IMN). Autoimmun Rev. 2016; 15: 146-54. doi: 10.1016/j.autrev.2015.10.004. 